\section{The scrotal elevator: a novel scrotal retractor for perineal approach surgery}

\section{Guy F. Nash}

Department of Surgery, Poole Hospital, Poole, Dorset, UK

Thorough examination under anaesthetic of the rectum and anus demands an adequate view of the perineum. Traditionally patients are placed in the Lloyd-Davies position when anorectal access is required. However, in male patients, the scrotum may obscure the perineum making it difficult to perform an ade-

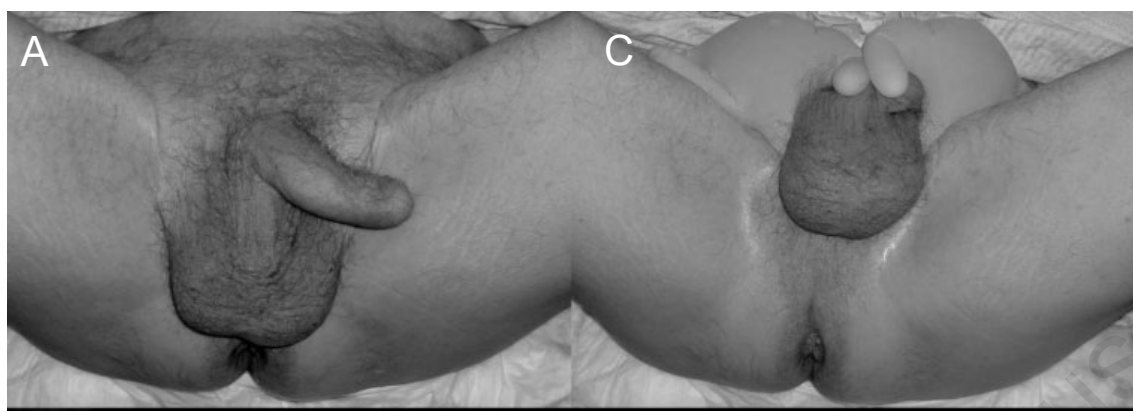

B

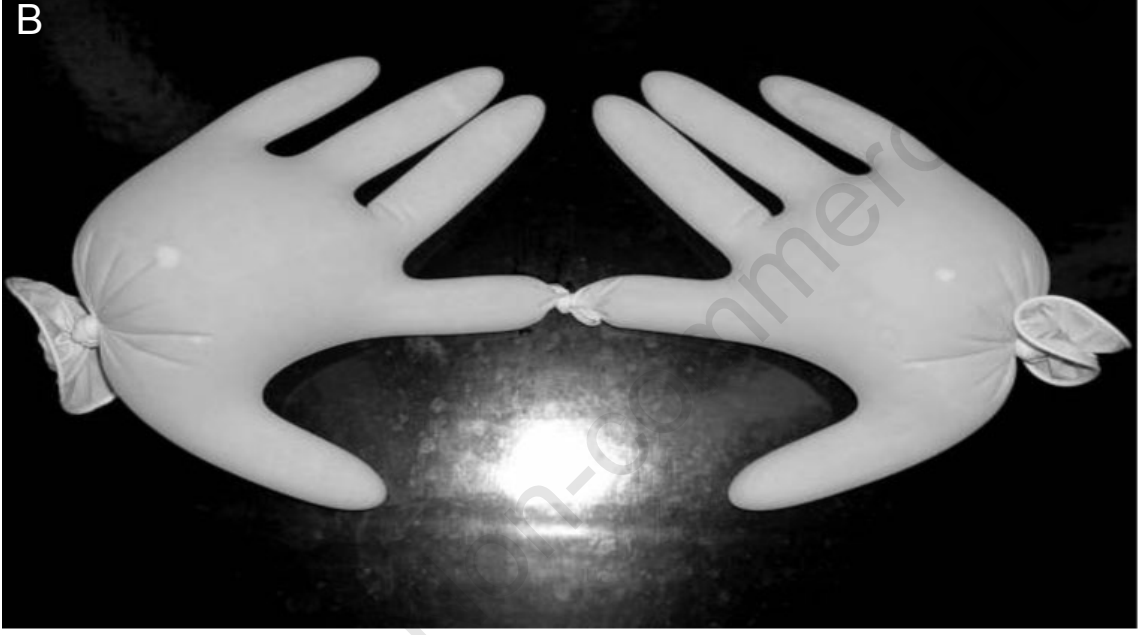

Figure 1. The operative view of the perineum before $(A)$ and after $(C)$ the use of the scrotal retractor, which seen here $(B)$ created by tying together the thumbs of surgical gloves which have been filled with water. quate examination (Figure 1A). Over the years, several methods have been used as makeshift retractors. We present an idea inspired by a St. Mark's prototype made from rubber tubing and two large stones from colorectal consultant Mr. Peter Macdonald's garden!

The scrotal elevator is made by tying together the index fingers of two water-filled, large disposable latex gloves (Figure 1B). The knotted finger section is placed underneath the scrotum with the palms lain over the thighs drawing the scrotum cranially (Figure 1C). We recommend this safe, effective and rapid method of scrotal retraction which has a total cost of one cent.
Correspondence: Guy F. Nash, Department of Surgery, Poole Hospital, Longfleet Road, Poole, Dorset BH15 2JB, UK.

Tel. 44.1202.442818 - Fax: 44.1202.442615.

E-mail: guy.nash@poole.nhs.uk

Key words: coloproctology, perineum, examination.

Conflict of interest: the authors report no conflicts of interest.

Received for publication: 14 June 2011

Accepted for publication: 30 June 2011.

This work is licensed under a Creative Commons Attribution NonCommercial 3.0 License (CC BYNC 3.0).

CC Copyright G.F. Nash, 2011

Licensee PAGEPress, Italy

Surgical Techniques Development 2011; 1:e doi:10.4081/std.2011.e3 